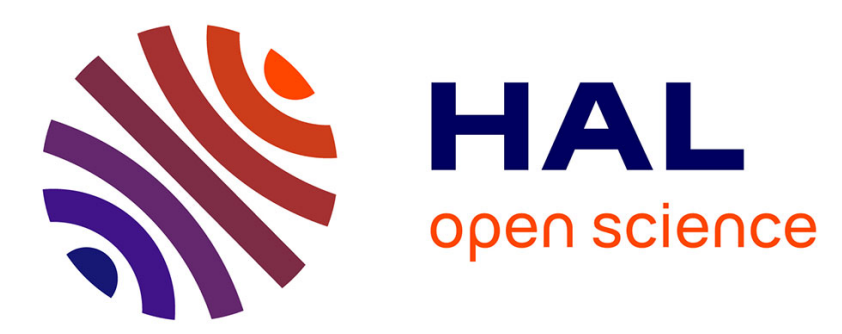

\title{
Risk Perception Biases and the Resilience of Ethics for Complying with COVID-19-Pandemic-Related Safety Measures
}

\author{
Bako Rajaonah, Enrico Zio
}

\section{To cite this version:}

Bako Rajaonah, Enrico Zio. Risk Perception Biases and the Resilience of Ethics for Complying with COVID-19-Pandemic-Related Safety Measures. Journal of Risk Analysis and Crisis Response, Atlantis Press, 2021, 11 (2), pp.87-90. 10.2991/jracr.k.210707.001 . hal-03048334

\section{HAL Id: hal-03048334 \\ https://hal.archives-ouvertes.fr/hal-03048334}

Submitted on 20 Jul 2021

HAL is a multi-disciplinary open access archive for the deposit and dissemination of scientific research documents, whether they are published or not. The documents may come from teaching and research institutions in France or abroad, or from public or private research centers.
L'archive ouverte pluridisciplinaire HAL, est destinée au dépôt et à la diffusion de documents scientifiques de niveau recherche, publiés ou non, émanant des établissements d'enseignement et de recherche français ou étrangers, des laboratoires publics ou privés.

\section{()ㅜ) $\Theta$}

Distributed under a Creative Commons Attribution - NoDerivatives| 4.0 International 
Title

RISK PERCEPTION BIASES AND THE RESILIENCE OF ETHICS FOR COMPLYING WITH COVID-19-PANDEMIC-RELATED SAFETY MEASURES

\section{Authors}

Bako Rajaonah ${ }^{1}$, Enrico Zio ${ }^{23}$

\section{Affiliations}

${ }^{1}$ Laboratory of Industrial and Human Automation control, Mechanical engineering and Computer Science (LAMIH UMR CNRS 8201), Université Polytechnique Hauts-de-France, Valenciennes, France

${ }^{2}$ Centre de Recherche sur les Risques et les Crises, MINES ParisTech/PSL Université Paris, Sophia Antipolis, France.

${ }^{3}$ Department of Energy, Politecnico di Milano, Milan, Italy.

\section{E-mail addresses}

Dr. Bako Rajaonah: bako.rajaonah@uphf.fr

Professor Enrico Zio: enrico.zio@mines-paristech.fr; enrico.zio@polimi.it

\section{Corresponding author}

- Dr. Bako Rajaonah

- bako.rajaonah@uphf.fr

- LAMIH, Université Polytechnique Hauts-de-France, Campus Mont Houy, Valenciennes, F59313

- $\quad$ Phone number: +332751 1491 


\title{
TITLE
}

RISK PERCEPTION BIASES AND THE RESILIENCE OF ETHICS FOR COMPLYING WITH COVID-19 PANDEMIC-RELATED SAFETY MEASURES

\begin{abstract}
This perspective paper presents factors that bias COVID-19-related risk judgments and risk decisions, such as cognitive biases, affect heuristics, mental models of risk and trust. The goal is to gain knowledge about the difficulty of risk communication in inducing attitudinal and behavioral changes regarding protective measures. Talking about morality and ethics appears to be less obsolete and more necessary than ever; it could even be seen as a 'spare tire' after one and a half years of risk communication and almost four million deaths. Perhaps it is time to think in terms of resilience at all levels, from the citizen of humanity to the highest institutions.
\end{abstract}

\section{KEYWORDS}

Risk perception; Resilience; Ethics; Mental models of risk; Trust; COVID-19 


\section{MOTIVATION}

After one year and a half of the COVID-19 pandemic, almost four million deaths ${ }^{1}$, and considerable socioeconomic damage worldwide, we extend a prior short communication ${ }^{2}$ to more thoroughly explore the relationships between risk judgment and the decision-making that risk judgment informs. Our goal is to raise the debate about risk communication, starting from the influences on risk perceptions and risk decisions of cognitive, affective and social factors - with an emphasis on mental models and trust - and ending with the concept of the ethics of resilience.

\section{INFLUENCES OF RISK JUDGMENTS AND RISK DECISIONS}

We choose the work of Breakwell [1] to summarize the determinants of risk judgments and decisions regarding individual protective behavior (i.e., mask wearing, physical distance keeping, contact tracing app usage, vaccination, movement restriction, and lockdown acceptance) (Table 1). Note that even though these influences are categorized here in terms of cognitive, personality, affective, and social factors for their readability, they interact with each other and provide different levels of explanation from the individual level to the institutional level.

Table 1 Cognitive, personality, affective, and social factors that influence risk judgment and decisionmaking from Breakwell [1]. The factors are in italics.

\section{Cognitive Factors}

Availability heuristic: Tendency to assume that the frequency or the probability of an event is greater if people can easily remember an instance of the event (p. 87). It can interact with confirmation bias, i.e., to favor paying attention to information that confirms existing hypotheses or beliefs (pp. 108109).

Anchoring bias: Tendency to rely too heavily on the first piece of information offered (the anchor) about a hazard (p. 90).

Confirmation bias: Tendency to favor paying attention to information that confirms existing hypotheses or beliefs (p. 108)).

Representativeness heuristic: Tendency to assume that the probability that an object $A$ belongs to a category $B$ (categorical judgment) is greater if $A$ resembles $B$ in some fashion (p. 86).

Optimistic bias: Tendency to believe to be less likely to experience negative events, and more likely to experience positive events, than other people (p. 91).

Mental model of risk: A system of beliefs, feelings and attitudes that the individual holds about the risk (p. 16), which can influence the way people use information and bring into play their heuristic biases (p. 103).

\section{Personality factors}

Perceived self-efficacy and locus of control: Representation of how much control individuals believe they have over what they do or what happens to them (p. 63).

\footnotetext{
${ }^{1}$ WHO: https://covid19.who.int/

${ }^{2}$ HAL Archives ouvertes : https://hal-uphf.archives-ouvertes.fr/hal-02533290v2
} 


\section{Affective factors}

Affect heuristic: Refers to the influence of the affect associated with the object of risk judgment and decision-making (p. 124, p. 131).

Feeling of risk: Refers to the primacy of emotion in the response to the hazard (p. 123).

\section{Social factors}

Group norms: Perceived norms of the group to which the individual belongs (p. 113) and

Cultural biases: Attitudes and beliefs shared by a group (p. 80).

Social trust: Comprising public trust (i.e., the amalgamated feelings of trust toward all societal institutions and leaders, the diffuse communal acceptance of the values of the system, p. 158), institutional trust (i.e., the general feeling of trust about a particular organization or social category, p. 109), and specific trust (i.e., the acceptance of the morals and feeling of confidence in a particular institution as it addresses a specific issue at a single time, p. 109).

In brief, risk judgments, and correlatively, risk decisions, are influenced by (i) heuristics; (ii) affective factors (e.g., feelings of confidence); (iii) mental models of risk including knowledge (e.g., virus transmissibility) and beliefs (e.g., self-efficacy), social and cultural norms (e.g., attitude toward mask wearing) and moral values (e.g., altruism); and (iv) trust as an engagement in action (e.g., intention to get vaccinated).

We decided to focus on mental models of risk and trust because the goal of risk communication is to (i) fill the gaps in the mental model with regard to risk understanding, reinforce correct beliefs, and correct misconceptions [2] and (ii) correct noncalibrated trust. However, let us begin with their common thread, the resilience of ethics.

\section{RESILIENT ETHICS \& RISK COMMUNICATION}

Resilience is defined by the United Nations Office for Disaster Risk Reduction as the ability of a system, community or society exposed to hazards to resist, absorb, accommodate, adapt to, transform and recover from the effects of a hazard in a timely and efficient manner [...].

Resilience relies not only on groups and communities but also on their members as individual responsible moral entities who are distinct from each other but influence each other within a given group or community. The challenge of COVID-19-related risk communication is not only to change individuals' attitudes until the pandemic is mastered but also to make people aware that there are critical contexts in which their perceived right way to behave is not necessarily the best with regard to these contexts. Resilient ethics refers here to some flexibility and adaptability ${ }^{3}$ of the moral values to fit with very critical situations that require attitudinal and behavioral change.

\footnotetext{
${ }^{3}$ https://www.collinsdictionary.com/dictionary/english/resilient
} 


\subsection{A Bit of Morality}

Communication must therefore be educative to make people see the hazard in a different way and persuasive to induce informed behavioral changes. Civic education programs could help to increase civic engagement, which would be beneficial in the long term [3]. Message design should be bidirectional and collaborative between government officials, experts and the public at large to acknowledge motives and needs and to avoid discordance between messages [4]. Messages should contain some types of moral lessons that address both individual and shared social and moral values to truly make messages an opportunity for attitude and behavior change: advocating altruism and prosocial behavior; emphasizing the effectiveness of protective measures at both personal and societal levels; emphasizing the sense of sacrifice for the greater benefit of society; developing a shared sense of identity; and encouraging the sense of cooperation $[3,5,6]$.

Repeating messages over and over is a good strategy to avoid familiarization with risk (especially relevant regarding the new variants!), which induces less perceived health risk and thus increases nonprotective behaviors, but it should also serve to avoid discouragement of people who make sacrifices; when they observe that other people "don't bother," they could feel unfairness and become less cooperative [7].

Communication should make the public aware of the impacts of the behavior of a handful of individuals across the whole society, for example, the extreme exhaustion of healthcare workers, the despair of people who lost their jobs, and increasing poverty: in short, all aspects of the socioeconomic fallout. Looking at these societal impacts, defending the value of individual freedom, for example, through organization of or participation in public demonstrations against COVID-19 restrictions, could be perceived as insulting given the millions of deaths.

However, values such as altruism are not sufficient. On the one hand, COVID-19 is considered to be challenging to humanity [8]; on the other hand, the philosopher Hans Jonas considered that humans were responsible for their actions regarding the future of nature and humanity [9]. His imperative of responsibility is a moral obligation that should be considered in education: we are responsible "for and to a distant future," and behaviors toward compliance with protective measures are part of respect for humanity. Given the threat due to the new variants, the morality issues in COVID-19 risk communication are less than ever obsolete and more than ever crucial. 


\subsection{Updating Mental Models of Risk}

The work on moral values can be reinforced by working on mental models, by filling the gap with regard to risk understanding, reinforcing correct beliefs, and correcting misconceptions [1]: knowledge about COVID-19 disease, especially the mechanisms of transmission and infectiousness, helps people to be more reflective in their judgments and to use less heuristics [10]. One way to enhance individuals' mental models of risk is to provide them with tools to better understand risk and its management. In the context of the present situation, Donnarumma and Pezzulo [11] suggest new educational strategies that make available to the public the relevant knowledge on cognitive and social sciences-e.g., regarding cognitive biases - to help them make informed decisions; providing statistical tools is also relevant, for example, to understand the concept of exponential growth, a mechanism that underlies the pandemic and that the lay public understands with difficulty [12]. The transmission process should be clearly explained to the public, for example, in the form of a mental model, such as the model suggested by Michie et $\mathrm{al}^{4}$.

\subsection{Trust: Whom? What?}

Finally, working on confidence and trust is also important because both appear to play an important role in the containment of the pandemic, even though there are no clear causal relationships: is noncompliance with protective measures truly due to a lack of trust? A strong sense of adherence to the values of a group (e.g., a political or religious group) could lead to unconditional affective support for or hostility toward, for example, behavioral recommendations. Is vaccine reluctance and hesitancy due to a lack of confidence toward the health system or to a lack of trust in a particular vaccine? Confidence is rather a feeling, while trust is a cognitive engagement in action [13]: the difference implies distinct communication guidelines. It is also important for appropriate communication to distinguish the object of confidence or trust, especially when different objects coexist for the same question and, therefore, different expectations, such as with COVID-19 vaccination, the literature reports various objects of trust: science, the health system, health care professionals, the localization of vaccine manufacturers, the effectiveness and safety of vaccines. Future studies could aim to clarify the content of expectations beyond all of these aspects of trust and confidence to design appropriate messages.

\footnotetext{
${ }^{4}$ BMJ Opinion: https://blogs.bmj.com/bmj/2020/03/11/slowing-down-the-covid-19-outbreak-changing-behaviour-byunderstanding-it/
} 


\subsection{Specific Recommendations}

At the time of the writing of this paper, COVID-19 vaccination is the center of attention in countries all over the world, because its success is necessary for the restart and recovery of normal social, economic, and political life. Therefore, Table 2 provides examples of recommendations to shape or update the beliefs that underlie both trust and mental models of risk regarding COVID-19 vaccination.

Table 2 Recommendations on communications that address vaccine hesitancy and vaccine refusal

Regarding the audience of messages [14,15]

- Localizing educational messages to specific audiences, without 'scientific slang'.

- Involving the public in the communication campaign. For example, involving students to elaborate messages and communicate them to their peers whom they trust (much more than they trust official institutions) via their usual social media platform; for an example, see: http:/fckitwontcutit.com/ (accessed 4 May 2021).

Regarding the fears related to vaccination and vaccines $[15,16]$

- Comparing vaccine risks to other daily risks and providing nonmathematical information using an emotive, empathic approach.

- Acknowledging that the transient side effects of vaccination mean that the vaccine is preparing the body to fight the disease, and that the risk of the COVID-19 disease is by far more important than the risks related to the COVID-19 vaccines.

- Educating people to weigh risks against benefits for vaccines, for example, by means of fact boxes ${ }^{5}$. Fact boxes present health information in an understandable and transparent manner (see: https://www.hardingcenter.de/sites/default/files/2020-05/methods_paper_Harding-Center_EN.pdf, accessed 5 May 2021).

Regarding the awareness of the necessity of vaccination

- Acknowledging that the new coronavirus is also harmful and deadly in younger age groups, i.e., the harmfulness is not limited to older populations and people with comorbidities. This aspect is particularly true with the new variants.

- Acknowledging that at this time, there is no scientific evidence that supports "natural" population immunity ${ }^{6}$, i.e., being protected through naturally acquired infection.

- Acknowledging that as a result, the best solution, as well as the most ethical solution, to achieving population immunity is vaccination ${ }^{7}$.

Regarding after vaccine uptake [17]

- Acknowledging the need for continuing protective behavior such as mask wearing and physical distancing after vaccination because of uncertainties regarding vaccine protection.

\section{CONCLUSIONS}

Let us conclude in terms of the ethics of resilience. Even the most sophisticated and successfully tailored messages will remain useless if vaccines are not available to everyone in all parts of the world. On 18 January 2021, WHO's Director-General declared that the world

\footnotetext{
${ }^{5}$ Scientific American: https://www.scientificamerican.com/article/few-would-fear-covid-vaccines-if-policy-makersexplained-their-risks-better/

${ }^{6}$ BMJ Opinion: https://blogs.bmj.com/bmj/2020/12/17/natural-herd-immunity-should-not-be-used-as-a-means-of-pandemiccontrol/

${ }^{7}$ WHO: https://www.who.int/publications/i/item/10665338400
} 
was "on the brink of a catastrophic moral failure," referring to the fact that higher-income countries had gone around COVAX (i.e., a collaborative project that aims at guaranteeing fair access to COVID-19 vaccines for every country in the world) ${ }^{9}$ by dealing directly with the manufacturers. Six months after this declaration, Reuters reported that approximately $47 \%$ of people who had received at least one dose of a vaccine were from high-income countries (with at least approximately $43 \%$ from Europe and North America) ${ }^{10}$.

Therefore, even if citizens are more flexible regarding their moral values and accept changing their habits to comply with protective behaviors, societal resilience cannot be achieved without ethics at higher levels than that of the citizen. We call this concept the ethics of resilience, in support of an integrated approach to risk and resilience management of disasters ${ }^{11}$. Concretely, the ethics of resilience implies respecting some moral imperatives throughout the four phases of disaster management (i.e., prevention/mitigation; protection/preparation; emergency and crisis response activities; recovery for restoring a normal or improved situation). Such an ethics could consider the seven principles of ethics for disasters proposed by the philosopher Naomi Zack [18]: general moral obligations to plan for and respond to disaster; adequacy (i.e., proportionality to benefit and inverse proportionality to risk) and fairness, with the rule of Fairly Save All Who Can Be Saved with the Best Preparation; individual responsibility; social contract obligations, i.e., governments are obligated to assist individuals in disaster-preparation and -response planning and implementation; safety and security, with a clear distinction regarding the treatment of public safety and public security; dignity, i.e., the human dignity of all disaster victims should be preserved as a primary oral value; and needs, i.e., the needs of all victims must be addressed. The ethics of resilience could also account for Jonas's collective imperative of responsibility for the distant future [9], as well as the englobing view of the interdependences between the various dynamics of a disaster, the various sources and natures of risk, and the spatial worldwide distribution of causes and effects [19,20]. Clearly, an enormous amount of work is waiting for the discipline of Disaster Risk Reduction.

\footnotetext{
${ }^{8}$ WHO: https://www.who.int/director-general/speeches/detail/who-director-general-s-opening-remarks-at-148th-session-ofthe-executive-board ${ }^{9}$ GAVI: https://www.gavi.org/covax-facility

${ }^{10}$ Reuters: https://graphics.reuters.com/world-coronavirus-tracker-and-maps/vaccination-rollout-and-access/

${ }^{11}$ Prof. Enrico Zio. "La resilienza etica, di necessità virtù." Il mondo, la casa comune, Solidarietà e sostenibilitaà, le opportinità per il nuevo ruolo, dell'imprenditore, FORUM PMI Cesano Maderno, 17 Giugno 2021.
} 


\section{CONFLICTS OF INTEREST}

The authors declare they have no conflicts of interest.

\section{ACKNOWLEDGMENTS}

The authors warmly thank the reviewers for their constructive comments.

\section{REFERENCES}

[1] G.M. Breakwell. The psychology of risk, 2nd edition. Cambridge University Press, Cambridge, United Kingdom, 2014.

[2] B. Fischhoff. Risk perception and communication unplugged. Twenty years of process. Risk Anal, 1995, Volume 15(2), 137-145. https://doi.org/10.1111/j.1539-6924.1995.tb00308.x.

[3] G. Alessandri, L. Filosa, M.S. Tisak, E. Crocetti, G. Crea, L. Avanzi. Moral disengagement and generalized social trust as mediators and moderators of rule-respecting behaviors during the COVID-19 outbreak. Front Psychol, 2020. https://doi.org/10.3389/fpsyg.2020.02102.

[4] L. Zhang, H. Li, K. Chen. Effective risk communication for public health emergency: Reflection on the COVID-19 (2019-nCoV) outbreak in Wuhan, China. Healthcare, 2020, Volume 8(1), 64. https://doi.org/10.3390/healthcare8010064.

[5] S. Dryhurst, C.R. Schneider, J. Kerr, A.L.J. Freeman, G. Recchia, A.M. van Der Bles. Risk perceptions of COVID-19 around the world. J Risk Res, 2020, Volume 23(7-8), 94-1006. https://doi.org/10.1080/13669877.2020.1758193.

[6] J.J. Van Bavel, K. Baicker, P.S. Boggio, V. Capraro, A. Cichocka, M. Cikara et al. (2020). Using social and behavioural science to support COVID-19 pandemic response. Nat Hum Behav, 2020, Volume 4, 460-471. https://doi.org/10.1038/s41562-020-0884-z.

[7] P.D. Lunn, C.A., Belton, C. Lavin, F.P. McGowan, S. Timmons, D. Robertson. Using behavioral science to help fight the Coronavirus: A rapid, narrative review. J Behav Public Adm, 2020, Volume 3(1). https://doi.org/10.30636/jbpa.31.147.

[8] A. Jones, N. Strigul. Is spread of COVID-19 a chaotic epidemic? Chaos Solitons Fractals, 2021, Volume 142, 110376. https://doi.org/10.1016/j.chaos.2020.110376.

[9] H. Jonas. Technology and responsibility: Reflections on the new tasks of ethics. Soc Res, 1973, Volume 40(1), 31-54.

[10] V. Thoma, L. Weis-Cohen, P. Filkulková, P. Ayton. Cognitive predictors of precautionary behavior during the COVID-19 pandemic. Front Psychol, 2021, Volume 12, 589800. https://doi.org/10.3389/fpsyg.2021.589800.

[11] F. Donnaruma, G. Pezzulo. Moral decisions in the age of COVID-19: Your choices really matter. Social Sciences \& Humanities Open, 2021, Volume 4(1). https://doi.org/10.1016/j.ssaho.2021.100149.

[12] R. Banerjee, J. Bhattacharya, P. Majumdar. Exponential-growth prediction bias and compliance with safety measures related to COVID-19. Soc Sci Med, 2021, Volume 268, 113473. https://doi.org/10.1016/j.socscimed.2020.113473.

[13] M. Hunyadi. Au début était la confiance [At the beginning was trust]. Éditions Le Bord de l'Eau, Lormont, France, 2020.

[14] S. Contera. Communication is central to the mission of science. Nature Reviews Material, 2021, Volume 6, 377-378. https://doi.org/10.1038/s41578-021-00316-w.

[15] S. Lewandowsky, J. Cook, P. Schmid, D.L. Holford, A. Finn (Lead authors). The COVID-19 Vaccine Communication Handbook. A practical guide for improving vaccine communication and fighting misinformation (Version 6). Available at: https://osf.io/f6a48/ (accessed 30 June 2021).

[16] C.M. Poland, A.K.S. Matthews, G.A. Poland. Improving COVID-19 vaccine acceptance: Including insights from human decision-making under conditions of uncertainty and human-centered. Vaccine, 2021, Volume 39(11), 1547-1550. https://doi.org/10.1016/j.vaccine.2021.02.008. 
[17] Z. Su, J Wen, D. McDonnel, E. Goh, X. Li, S. Šegalo et al. Vaccines are not yet a silver bullet: The imperative of continued communication about the importance of COVID-19 safety measures. Brain Behav Immun, 2021, Volume 12, 100204. https://doi.org/10.1016/j.bbih.2021.100204.

[18] N. Zack. Ethics for disasters. Rowman \& Littlefield Publishers, Inc., Lanham (MD), 2010.

[19] T. Thoradeniya, S. Jayasinghe. COVID-19 and future pandemics: A global systems approach and relevance to SDGs. Global Health, 2021, Volume 17(59). https://doi.org/10.1186/s12992-021-00711-6.

[20] T. Aven, E. Zio. Globalization and global risk: How risk analysis needs to be enhanced to be effective in confronting current threats. Reliab Eng Syst Saf, 2021, Volume 205, 107270. https://doi.org/10.1016/j.ress.2020.107270. 